\title{
S6 Kinase Reflects and Regulates Ethanol-Induced Sedation
}

\author{
Summer F. Acevedo, ${ }^{1}$ Raniero L. Peru y Colón de Portugal, ${ }^{1,2}$ Dante A. Gonzalez, ${ }^{1,2}{ }^{\circledR}$ Aylin R. Rodan, ${ }^{3}$ \\ and Adrian Rothenfluh ${ }^{1,2}$ \\ ${ }^{1}$ Department of Psychiatry, ${ }^{2}$ Program in Neuroscience, and ${ }^{3}$ Department of Internal Medicine, Division of Nephrology, University of Texas Southwestern \\ Medical Center, Dallas, Texas 75390
}

Alcohol use disorders (AUDs) affect people at great individual and societal cost. Individuals at risk for AUDs are sensitive to alcohol's rewarding effects and/or resistant to its aversive and sedating effects. The molecular basis for these traits is poorly understood. Here, we show that p70 S6 kinase (S6k), acting downstream of the insulin receptor (InR) and the small GTPase Arf6, is a key mediator of ethanolinduced sedation in Drosophila. S6k signaling in the adult nervous system determines flies' sensitivity to sedation. Furthermore, S6k activity, measured via levels of phosphorylation (P-S6k), is a molecular marker for sedation and overall neuronal activity: P-S6k levels are decreased when neurons are silenced, as well as after acute ethanol sedation. Conversely, P-S6k levels rebound upon recovery from sedation and are increased when neuronal activity is enhanced. Reducing neural activity increases sensitivity to ethanol-induced sedation, whereas neuronal activation decreases ethanol sensitivity. These data suggest that ethanol has acute silencing effects on adult neuronal activity, which suppresses InR/Arf6/S6k signaling and results in behavioral sedation. In addition, we show that activity of InR/Arf6/S6k signaling determines flies' behavioral sensitivity to ethanol-induced sedation, highlighting this pathway in acute responses to ethanol.

Key words: addiction; Arf6; Drosophila; ethanol; insulin receptro; S6 kinase

\section{Significance Statement}

Genetic factors play a major role in the development of addiction. Identifying these genes and understanding their molecular mechanisms is a necessary first step in the development of targeted therapeutic intervention. Here, we show that signaling from the insulin receptor in Drosophila neurons determines flies' sensitivity to ethanol-induced sedation. We show that this signaling cascade includes the small GTPase Arf6 and S6 kinase (S6k). In addition, activity of S6k is regulated by acute ethanol exposure and by neuronal activity. S6k activity is therefore both an acute target of ethanol exposure and a regulator of ethanol's effects on behavior.

\section{Introduction}

Alcohol use disorders (AUDs) and alcoholism have significant consequences for individuals and society at large. People at risk for AUDs are more sensitive to the positive, "rewarding" effects of ethanol exposure and/or are more resistant to its intoxicating

Received May 15, 2015; revised Sept. 26, 2015; accepted Oct. 13, 2015.

Author contributions: S.F.A., R.L.P.y.C.d.P., D.A.G., A.R.R., and A.R. designed research; S.F.A., R.L.P.y.C.d.P., and D.A.G. performed research; S.F.A., R.L.P.y.C.d.P., D.A.G., and A.R. analyzed data; S.F.A., R.L.P.y.C.d.P., A.R.R., and A.R. wrote the paper.

This work was supported by the National Institutes of Health (Grant T32 DA007290 to R.L.P. and D.A.G., Grant K08DK091316 to A.R.R., and Grant R01AA019526 to A.R.). A.R. was also supported by an Effie Marie Cain Scholarship in Biomedical Research from University of Texas Southwestern Medical Center. We thank Thomas Neufeld for donating anti S6k antibody, the Bloomington and Kyoto stock centers for fly strains, and members of the Rothenfluh laboratory, Robin Hiesinger, and Michael Buszczak for critical discussions.

The authors declare no competing financial interests.

Correspondence should be addressed to Adrian Rothenfluh, Department of Psychiatry, UT Southwestern Medical Center, 5323 Harry Hines Blvd., Dallas, TX 75390-9127. E-mail: Adrian.Rothenfluh@UTSouthwestern.edu.

R.L. Peru y Colón de Portugal's present address: Department Molecular and Cellular Biology, Harvard University, Boston, Massachusetts.

DOI:10.1523/JNEUROSCI.1880-15.2015

Copyright $\odot 2015$ the authors $\quad 0270-6474 / 15 / 3515396-07 \$ 15.00 / 0$ and sedating effects (Newlin and Thomson, 1990; Schuckit, 1994; King et al., 2011; Quinn and Fromme, 2011). Although numerous studies indicate that alcoholism has a large genetic component (Goldman and Ducci, 2007; Gelernter and Kranzler, 2009; Rietschel and Treutlein, 2013), our understanding of the genes and molecules contributing to AUDs is still lacking.

Drosophila melanogaster, the vinegar fly, is a genetically tractable organism used to model ethanol-induced behaviors relevant to AUDs (Rodan and Rothenfluh, 2010; Kaun et al., 2011). As in mammals, low doses of ethanol induce disinhibition (Lee et al., 2008) and hyperlocomotion (Wolf et al., 2002), whereas high doses cause loss of postural control and sedation (Rothenfluh et al., 2006). In addition to the behavioral similarities between flies and mammals, there is also substantial mechanistic overlap. For example, proper regulation of the actin cytoskeleton is required in mammals and flies for normal behavioral responses to ethanol. Mice with a genetic knock-out of EPS8, an actin-capping protein, are resistant to ethanol-induced sedation and they drink more alcohol (Offenhäuser et al., 2006). In flies, the small Rho-family GTPase Rac1, a regulator of actin dynamics, is required for nor- 
mal ethanol responses (Rothenfluh et al., 2006) and we have shown recently that the Arfaptin protein links Racl to another small GTPase, Arf6 (Peru y Colon de Portugal et al., 2012). Arf6 is important in membrane trafficking and actin organization at the plasma membrane (Palamidessi et al., 2008; Schweitzer et al., 2011) and its loss causes sensitivity to ethanol-induced sedation (Peru y Colon de Portugal et al., 2012). Genetically, Arf6 acts downstream of Rac1, but other components acting in concert with Arf6 to modulate ethanol-induced sedation are currently not known.

Here, we show that Arf6 acts in the insulin receptor ( InR) signaling pathway both in vivo and in Drosophila cell culture. Arf6 is required for insulin-induced activation of S6 kinase (S6k) and adult neuronal activity of the pathway correlates with the degree of resistance to ethanol-induced sedation. In addition, we show that the pathway is also acutely regulated by ethanol and that sedation correlates with the loss of S6k activity, as measured by loss of S6k phosphorylation (P-S6k). Activity of S6k is thus both a molecular marker and a behavioral determinant for ethanolinduced sedation. Last, we show that neuronal inhibition causes loss of P-S6k and facilitates ethanol-induced sedation, whereas the opposite is true for neuronal activation. Our findings suggest that acute ethanol causes neuronal silencing and that InR signaling is under dynamic regulation by neural activity and by acute ethanol. Neuronal InR/Arf6/S6k signaling also determines the level of sensitivity to ethanol-induced sedation.

\section{Materials and Methods}

Fly stocks, genetics, and behavioral experiments. Flies were maintained on regular cornmeal/yeast/molasses at $25^{\circ} \mathrm{C} / 65 \%$ humidity (unless otherwise specified). Flies were out-crossed for at least five generations to the $w^{\star}$ Berlin (wild-type) genetic background. The following fly strains were obtained from the Bloomington stock center: $\operatorname{Arf6}^{\mathrm{P} 2}$ (EP2612, \#17076), $\operatorname{Arf6}^{\mathrm{KG}}$ (KG02753, \#13763), and UAS-TrpA (\#26264). Arf6 ${ }^{\mathrm{G} 4}$ was obtained from the Kyoto stock center (NP5226, \#104910). UAS-shi ${ }^{\text {ts }}$ on the second chromosome was a gift from Toshi Kitamoto. Drivers used were elav-Gal4, which expressed pan-neuronally, and whir ${ }^{1}-G a l 4 /+$ and whir ${ }^{3}$-Gal4/+. The latter two are expressed more specifically in the brain in neurons requiring both Arf6 (Peru y Colon de Portugal et al., 2012) and RhoGAP18B (Rothenfluh et al., 2006) for normal ethanol-induced sedation. Of the two, whir ${ }^{3}$-Gal4/+ expresses Gal4 more strongly (Rothenfluh et al., 2006), but flies containing whir $^{3}$-Gal4/+ and UAS$\operatorname{Trp} A$ had seizures even at room temperature and we therefore used the weaker whir ${ }^{1}-G a l 4 /+$ for the experiments shown in Figure 6. Because the whir gene is on the X chromosome, we used (whir-Gal4/+ heterozygous) females for these experiments (see Figs. $2 A, B, 6$ ). For all other experiments, males were used.

Ethanol exposure and determination of the ST-50 via measuring the flies' loss-of-righting reflex in the Booz-o-mat was performed as described previously (Rothenfluh et al., 2006). In brief, groups of 20 flies per tube (for an $n$ of 1 ) were exposed to vaporized ethanol (130/20 ethanol/air flow rate, unless specified otherwise) and manually counted for loss-of-righting reflex at $5 \mathrm{~min}$ intervals until 50\% of the flies were unable to right themselves upon gentle tapping. Our previous studies indicate that systemic levels of ethanol in flies at the ST50 using 150/0 ethanol/air concentration is $\sim 17 \mathrm{~mm}$ (Peru y Colon de Portugal et al., 2012), which is about equivalent to the legal driving limit of alcohol in humans ( $\sim 0.08 \%$ blood alcohol concentration). Flies' locomotion activity was measured for $3 \mathrm{~d}$ in a 12:12 h light:dark cycle with a standard circadian rhythm Drosophila Activity Monitor system (Trikinetics). In it, single flies are kept in a small glass cuvette with food and an infrared emitter and detector measures their beam breaks in 30 min bins.

Rapamycin feeding treatment. Rapamycin (LC Laboratories) was dissolved in ethanol to make $1 \mathrm{~m}$ stock solutions. Flies were fed rapamycin on filter paper (final concentration: $400 \mu \mathrm{M}$ rapamycin in $100 \mathrm{~mm}$ sucrose) for 3 consecutive days at $25^{\circ} \mathrm{C}$ before testing. Control flies were fed

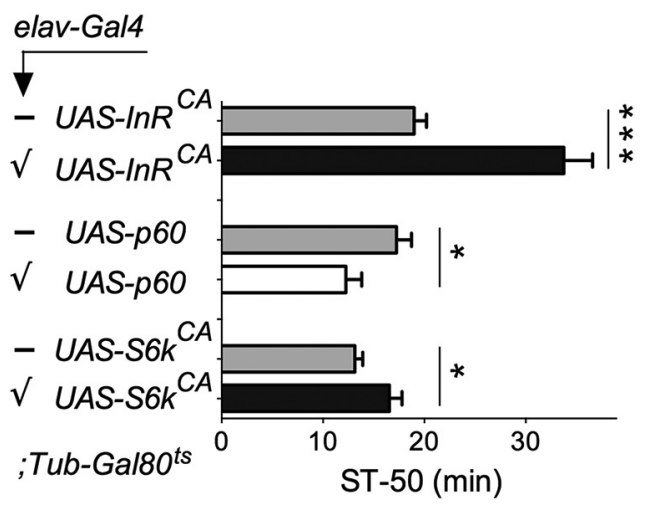

Figure 1. Adult neuronal InR signaling regulates ethanol-induced sedation. Adult neuronal expression of constitutively activated InR (UAS-InR ${ }^{\text {CA. }}$ Student's $t$ test, ${ }^{* * *} p<0.001, t=5.4$, $n=8,12$, where an $n$ of 1 is a group of 20 flies) or the downstream effector S6k (UAS-S6k ${ }^{\text {CA } ; ~} t$ test, ${ }^{*} p<0.05, t=2.4, n=8,10$ ) led to reduced sensitivity to ethanol-induced sedation. Neither of the two altered overall locomotor activity (total daily counts: $1662 \pm 147$ for elavGal4; UAS-InR ${ }^{\text {CA }}$ vs $1969 \pm 154$ for control; $t$ test, $p=0.16, t=1.4, n=16$, where an $n$ of $1=$ 1 fly; and $1400 \pm 149$ for elav-Gal4;UAS-S6k ${ }^{\text {CA }}$ vs $1569 \pm 130$ for control; $t$ test, $p=0.40, t=$ $0.85, n=16$ ). Conversely, adult neuronal expression of the Pi3k inhibitor p60 (UAS-p60; $t$ test $\left.{ }^{*} p<0.05, t=2.3, n=9,8\right)$ causes increased sensitivity to ethanol. Flies were exposed to $130 / 20$ ethanol/air (E/A), and results are shown as means \pm SEM. Gal4 activity was repressed by growing flies at $18^{\circ}$ during development with expression of the temperature-sensitive Gal4 repressor Gal $80^{\text {ts }}$. Adults were placed at $29^{\circ}$ for $3 \mathrm{~d}$ to inactivate Gal $80^{\text {ts }}$, thus allowing Gal4induced UAS-transgene expression. (Note that pharmacological inhibition of mTOR by feeding adults rapamycin also caused ethanol sensitivity; see Results.)

$100 \mathrm{~mm}$ sucrose with equivalent amounts of ethanol as in the experimental condition.

Cell culture. Drosophila S2-Gal4 cells were maintained at $26^{\circ} \mathrm{C}$ in Schneider medium (Invitrogen) with $10 \%$ fetal bovine serum. Constructs were made using Gateway cloning (T. Murphy, Carnegie, Baltimore, $\mathrm{MD}$ ) and clonase (Invitrogen) and transfected using a standard calcium chloride protocol. A stably transfected Arf6 ${ }^{\mathrm{Q} 67 \mathrm{~L}}$ (Arf6 ${ }^{\mathrm{CA}}$ ) line was generated with pCoHygro (Invitrogen) and maintained in the presence of 22 $\mathrm{mg} / \mathrm{ml}$ hygromycin in the medium. Anti-Arf6 dsRNAi was generated using the Megascript T7 kit (Ambion) and cells were treated daily for $3 \mathrm{~d}$ with $15 \mu \mathrm{g}$ of dsRNAi. Serum-starved cells were treated with bovine insulin (Sigma-Aldrich) or wortmannin (150 nM; LC Laboratories) for 30 min before harvesting.

Antibody techniques. Western blots were performed using anti-Arf6 antibody (1:1000, Sigma-Aldrich, \#A5230), anti-S6k (1:1000 a gift from Thomas Neufeld, University of Minnesota), anti-P-S6k (1:2000, \#9206, Cell Signaling Technology) and visualized using enhanced chemiluminescence (GE Healthcare). Densitometry was conducted using the Adobe Photoshop Creative Suite 3 (CS3) analysis tool. Each $n$ of 1 consist of the ratio of mean gray value relative to background, which was then averaged with three separate blots probed with both anti-S6k and antiP-S6k taken from three independent biological replicates. Arf6.GTP levels were determined using the Active Arf6 pull-down and detection kit (\#16122Y; Thermo Scientific) and compared with total Arf6 (Sigma-Aldrich, \#A5230) in the lysate in three independent pulldown experiments.

Statistical analysis. Data were analyzed using Prism software (GraphPad). Student's $t$ test or ANOVA followed by Dunnett's post hoc comparisons were conducted when appropriate. A $p<0.05$ was considered significant.

\section{Results}

Previously, we isolated mutations in Arf6 and showed that they cause sensitivity to ethanol-induced sedation (without affecting overall locomotor activity; Peru y Colon de Portugal et al., 2012). In mammalian HepG2 liver cell culture, Arf6 has been shown to participate in InR signaling (Lim et al., 2010), but in 3T3-L1 adipocytes, Arf6 is not required for activation of InR downstream 
A

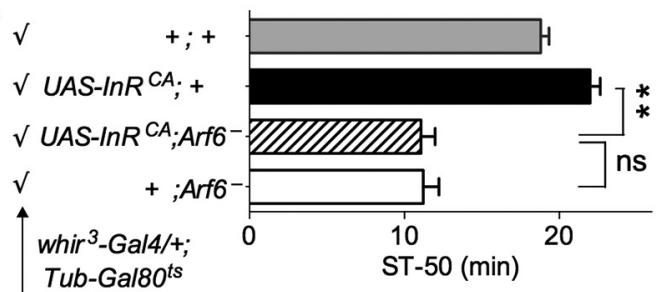

B

$\checkmark$

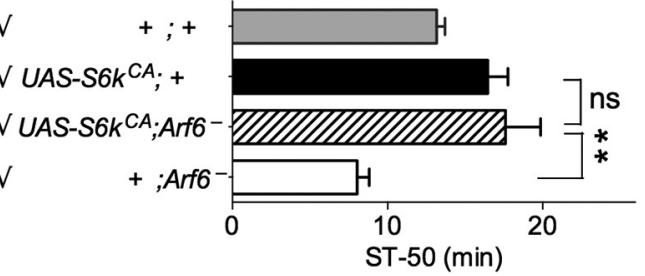

C anti-Arf6 blot: flies

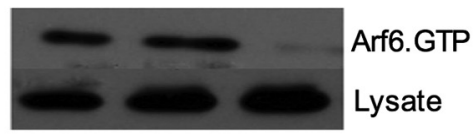

$-\frac{C A \quad D N}{U A S-I n R}$

D

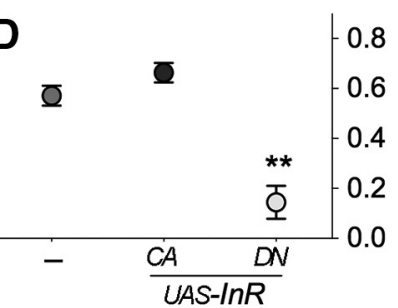

E anti-Arf6 blot: S2 cells

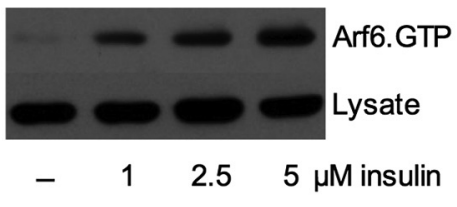

$\mathbf{F}$

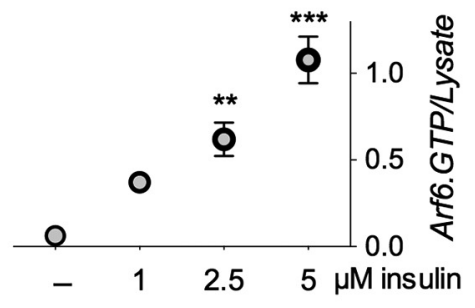

Figure 2. Arf6 functions downstream of InR and upstream of $S 6 \mathrm{k}$ to control ethanol responses. $A$, Arf6 double mutants with UAS-InR ${ }^{C A}$ are as sensitive as $A r f 6$ mutants alone $\left(F_{(3,29)}=54\right.$ for overall differences, $p<0.001, n=8,12,7,6$; one-way ANOVA with Dunnett's post hoc test: $n s p=0.99, q=0.12$ ) and more sensitive than UAS-InR ${ }^{\mathrm{CA}}$ alone ${ }^{* *} p<0.01, q=10.6 ; 130 / 20$ ethanol/air (E/A)]. B, Arf6 double mutants with ethanol-resistant UAS-S6k ${ }^{\text {CA }}$ are as resistant as UAS-S6k ${ }^{\mathrm{CA}}$ mutants $\left(F_{(3,36)}=12\right.$ for overall differences, $p<0.001, n=13,12,6,9 ;$ one-way ANOVA with Dunnett's post hoc test: $n s p=0.99, q=0.64)$ and significantly more resistant than Arf6 mutants alone $\left({ }^{* *} p<0.01, q=5.0\right)$. C, D, Pull-down of activated Arf6.GTP followed by anti-Arf6 Western blot of UAS-InR flies shows significant downregulation of Arf6 activation with dominant-negative InR compared with control without transgene $\left(F_{(2,6)}=31\right.$ for overall differences, $p<$ 0.001 , one-way ANOVA with Dunnett's post hoc test: $\left.n=3,{ }^{* *} p<0.01, q=6.0\right)$. $\boldsymbol{E}, \boldsymbol{F}$, Pull-down in serum-starved $\mathbf{S} 2$ cells shows that 30 min of incubation with insulin causes dose-dependent activation of Arf6 ( $p<0.001, r^{2}=0.89$, Pearson's correlation coefficient; one-way ANOVA with Dunnett's post hoc test, $n=3:{ }^{* *} p<0.01, q=4.7,{ }^{* * *} p<0.001, q=8.5$ vs negative control).

targets (Li et al., 2012). To investigate whether Arf6 plays a role in InR signaling in the context of behavioral ethanol responses, we first investigated whether changes in InR signaling would affect ethanol-induced sedation in ways similar to changes in Arf6 (Peru y Colon de Portugal et al., 2012). Previous studies have found that suppression of InR signaling during development caused subsequent resistance to ethanol sedation in adults (Eddison et al., 2011; McClure et al., 2011). Because we showed previously that Arf6 is required in the adult nervous system for normal ethanol sedation behavior (Peru y Colon de Portugal et al., 2012), we specifically examined the consequences of changes in InR signaling in the adult nervous system. We used flies expressing the pan-neuronal driver elav-Gal4 together with the ubiquitous temperature-sensitive Gal4-inhibitor Gal80 ${ }^{\text {ts }}$ (Tub$\left.G a l 80^{\text {ts }}\right)$ to express a constitutively active $\mathrm{InR}, U A S-I n R^{\mathrm{CA}}$ and found that adult-only expression of the UAS-InR ${ }^{\mathrm{CA}}$ led to reduced sensitivity to ethanol-induced sedation, leaving flies' locomotor activity unchanged (Fig. 1). Adult neuronal expression of the activated downstream effector UAS-S6 ${ }^{\mathrm{CA}}$ also caused reduced ethanol sensitivity without changing overall locomotion (Fig. 1). Conversely, adult-specific inhibition of the InR signaling pathway, via expression of an inhibitor of phosphatidylinositol 3-kinase (Pi3k), UAS-p60 (Weinkove et al., 1999), caused an increase in ethanol sensitivity (Fig. 1). To confirm pharmacologically these findings that sensitivity to ethanol-induced sedation inversely correlates with the activity of the InR pathway, we fed adult wild-type flies for $3 \mathrm{~d}$ with $400 \mu \mathrm{m}$ rapamycin, an inhibitor of the S6k activator mTOR (mechanistic target of rapamycin; Bjedov et al., 2010) and found that this treatment increased sensitivity to ethanol (ST-50 for rapamycin-fed flies $=10.3 \pm 0.3 \mathrm{~min}$; for vehicle-fed flies $=12.9 \pm 0.7, p<0.05, t=3.3, n=4$, Student's $t$ test). Together, these data indicate that the activity of neuronal InR signaling in adult flies determines the sensitivity to ethanol-induced sedation, just as is the case for Arf6 activity (Peru y Colon de Portugal et al., 2012), and they are consistent with the hypothesis that Arf6 is required for mediating $\mathrm{InR}$ signaling.

To test genetically whether Arf6 acts in this pathway in vivo, we performed genetic epistasis experiments. We used the whir ${ }^{3}$ -
Gal4 driver, which expresses more specifically in neurons involved in ethanol-induced sedation (Rothenfluh et al., 2006), including neurons requiring Arf6 for normal ethanol-induced sedation (Peru y Colon de Portugal et al., 2012). Adult expression of activated InR in these neurons (whir ${ }^{3}$-Gal4/+; UAS$\operatorname{InR} \mathrm{CA} /+$ ) caused reduced ethanol sensitivity. Introducing an Arf6 ${ }^{-}$mutation in these flies expressing InR ${ }^{\mathrm{CA}}$ led to enhanced ethanol sensitivity in the double mutants that was indistinguishable from flies with only $A r f 6^{-}$mutation on its own (Fig. 2A). These results indicate that Arf6 acts downstream of InR in the regulation of ethanol-induced sedation. Conversely, reduced ethanol sensitivity of whir $^{3}-$ Gal4/+;UAS-S6k $k^{\mathrm{CA}} /+$ flies was not altered by the introduction of the ethanol-sensitive $A r f 6^{-}$mutation (Fig. 2B), which suggested that S6k acts downstream of Arf6 in the regulation of ethanol-induced sedation.

We next investigated whether InR signaling affected Arf6 activation in vivo and performed pull-down experiments with a bait protein, GGA3, that specifically recognizes activated, GTPbound Arf6 (Arf6.GTP). Flies expressing UAS-InR ${ }^{\mathrm{CA}}$ showed a slight, but nonsignificant, increase in Arf6 activation, whereas neuronal expression of dominant-negative $U A S-I n R^{\mathrm{DN}}$ led to a significant reduction in Arf6 activation (Fig. $2 C, D$ ). These data show that neuronal InR signaling affects Arf6 activity and that Arf6 mediates InR signaling, regulating ethanol-induced sedation.

To find a Drosophila cell culture model in which Arf6 was similarly downstream of InR, we examined wild-type Schneider $\mathrm{S} 2$ cells. We observed that insulin application on serum-starved cells resulted in a dose-dependent activation of Arf6 (Fig. 2 E, F) and also caused dose-dependent activation of S6k, as assessed with a phosphospecific antibody against phosphorylated S6k threonine 398 (P-S6k; Lizcano et al., 2003; Fig. 3A,D). As expected, this activation was suppressed by the Pi3k inhibitor wortmannin (Fig. 3A,D). RNAi-mediated knock-down of Arf6 suppressed S6k activation (Fig. 3B,D), whereas expression of GTP-locked, constitutively active Arf6 ${ }^{\text {Q67L }}$ (Arf6.GTP) increased baseline P-S6k levels, potentiated insulin's effect on S6k activation, and required higher levels of wortmannin for inhibition (Fig. 3C,D). These data show that Arf6 mediates S6k activation 
A

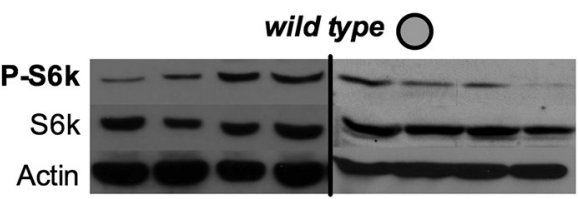

B

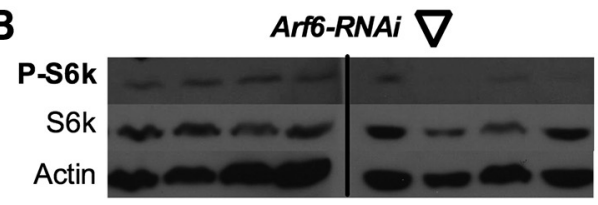

C
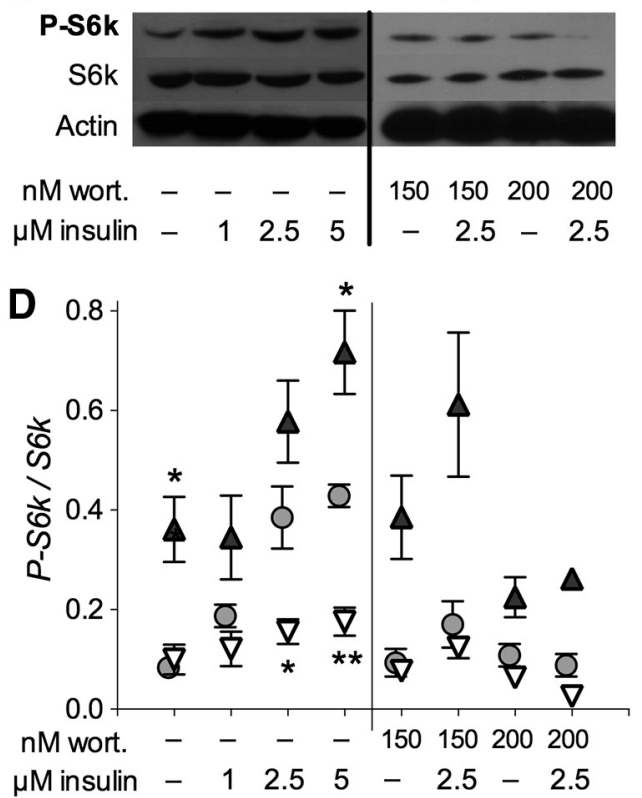

Figure 3. Arf6 mediates insulin-induced S6k activation in serum-starved S2 cells. $\boldsymbol{A}$, Western blot showing dose-dependent $\$ 6 \mathrm{k}$ activation (left half), inhibited by wortmannin (right half, cf. lanes 2 and 4 on the right with lane 3 on the left). $\boldsymbol{B}$, S6k activation is reduced after Arf6 knock-down by RNAi, whereas stable transfection of activated Arf6.GTP (C) potentiates S6k activation. $\boldsymbol{D}$, Quantification of three independent blots shown in $\boldsymbol{A}-\boldsymbol{C}$. S6k is activated in a dose-dependent manner by insulin (left, gray circles, $p<0.001, r^{2}=0.77$, Pearson's correlation coefficient). Altering Arf6 activity changes P-S6k levels (left, genotype main effect, $p<$ $0.001, F_{(2,24)}=48$, two-way ANOVA), with RNAi-mediated knock-down decreasing them $\left({ }^{*} p<0.05, q=3.1,{ }^{* *} p<0.01, q=3.4\right.$; Dunnett's post hoc test, $\left.n=3\right)$ and activated Arf6.GTP increasing them $\left({ }^{*} p<0.05, q=2.6,{ }^{* *} p<0.01, q>3.7\right.$; Dunnett's post hoc test, $n=3$ ). Wortmannin (right) significantly inhibited P-S6k at $2.5 \mu \mathrm{m}$ insulin (dose main effect $p<0.001, F_{(2,18)}=12$; two-way ANOVA).

induced by InR activation in Drosophila S2 cells, as it does in neurons in vivo.

The above in vivo data indicated that the level of activity of the InR signaling pathway determines the degree of resistance to ethanol-induced sedation. We next investigated whether ethanol exposure had any acute effects on InR signaling. We found that low doses of ethanol showed a trend toward potentiation of InR signaling, reflected in an increase in both Arf6 and S6k activation (Fig. 4). Conversely, high doses of ethanol suppressed InR signaling: Arf6.GTP levels were significantly decreased and P-S6k became undetectable (Fig. 4). The ethanol-induced loss of P-S6k levels was correlated with ethanol-induced behavioral sedation $\left(p<0.05\right.$, Pearson's $\left.r^{2}=0.27, n=15\right)$. Flies lacking Arf6, which are very sensitive to ethanol (Fig. 2), showed very little P-S6k regardless of ethanol exposure (Fig. 4C,D). If lack of P-S6k cor- relates with sedation, then this would suggest that Arf6 mutant flies might already be close to sedation before ethanol exposure. Indeed, Arf6 mutants sedate with very low levels of ethanol exposure that fail to sedate wild-type flies and these mutants are more sensitive than other known ethanol-sensitive mutants (Peru y Colon de Portugal et al., 2012). This suggests that acute loss of P-S6k correlates with ethanol-induced sedation and that genetic lack of P-S6k predisposes flies to sensitivity to ethanol-induced sedation.

To further test the inverse correlation between S6k activity and ethanol-induced sedation, we performed sedation recovery experiments. The speed of recovery from sedation depends on the ethanol dose (i.e., exposure time) that caused the sedation, with longer exposures leading to slower behavioral recovery (Fig. $5 D)$. We measured the percentage of awake flies and of P-S6k after three different exposure doses/lengths at three successive recovery time points. Levels of sedation and of P-S6k were negatively correlated both during exposure (Fig. 5A-C, $p<0.001$, Pearson's $r^{2}=0.73, n=12$ ) and during recovery (Fig. $5 D-F, p<$ 0.001 , Pearson's $\left.r^{2}=0.49, n=27\right)$. S6k activity therefore reflects acute sedation during exposure and recovery from ethanol (Figs. $4,5)$ and also determines the levels of sensitivity to ethanolinduced sedation (Figs. 1, 2).

We then turned our attention to understanding the physiological process responsible for the loss of P-S6k and ethanolinduced sedation. A recent report showed that, in the rodent brain, phosphorylation of the S6 ribosomal subunit, the canonical S6k substrate, is a molecular marker for neuronal activity (Knight et al., 2012). To test whether this was also true in Drosophila, we used the whir ${ }^{1}$-Gal4/+ driver (which, like whir ${ }^{3}$ Gal4/+, is expressed in the same neurons important for ethanol resistance, but expresses less strongly; Rothenfluh et al., 2006) to drive temperature-sensitive $U A S-s h i^{\text {ts }}$ to silence (Kitamoto, 2001) and UAS-TrpA to activate (Hamada et al., 2008) neurons, respectively. Flies in which neurons were silenced had decreased P-S6k levels, whereas flies with neuronal activation showed increased P-S6k (Fig. 6A, B). As in mammals, P-S6k activity in flies thus reflects neuronal activity and we hypothesized that loss of P-S6k caused by ethanol exposure was a reflection of loss of neuronal activity. If so, neuronal silencing should enhance ethanolinduced sedation, whereas neuronal activation should suppress it. Flies expressing UAS-TrpA driven by whir $^{1}$-Gal4/+ showed some incidence of seizures at $34^{\circ} \mathrm{C}$, so we assayed these flies at $32^{\circ} \mathrm{C}$, where they showed normal behavior in the absence of ethanol. As hypothesized, neuronal activation suppressed sedation, whereas neuronal silencing of whir ${ }^{1}$-Gal4 expressing neurons enhanced ethanol-induced sedation (Fig. 6D). At the ineffective temperature, $U A S$-shits ${ }^{\text {ts }}$ showed no effect on sedation, whereas $U A S-\operatorname{Trp} A$ had a significant effect that was smaller than at the high temperature. This may be due to leakiness of the TrpA channel (cf. Liu et al., 2012; Fig. 6C). These findings thus show that activity of S6k is a reflection of neuronal activity in Drosophila and suggest that ethanol causes sedation by acutely suppressing neuronal activity and thereby S6k activity.

\section{Discussion}

Insulin signaling in the nervous system regulates behavioral response to ethanol

Identifying the molecular mechanisms mediating ethanolinduced sedation is critical for understanding the development of AUDs. Here, we show that neuronal InR to S6k signaling is an important pathway in regulating ethanol-induced sedation. We found that adult-specific reduction in InR signaling causes in- 
creased sensitivity to ethanol's sedating effects, whereas activation of the pathway caused reduced ethanol sensitivity. These findings are consistent with initial reports showing that constitutive global and neuron-specific reductions in InR signaling caused sensitivity to ethanol-induced sedation (Corl et al., 2005). We also show that the small GTPase Arf6, which we have shown previously to act in the adult nervous system to regulate ethanol sedation (Peru y Colon de Portugal et al., 2012), acts downstream of InR. Arf6 activation reflects the activity of InR signaling both in the nervous system of flies and in hematocyte-derived Drosophila S2 cells. Unlike flies lacking other essential core components of the insulin signaling pathway, such as InR (Corl et al., 2005) and S6k (Montagne et al., 1999), flies lacking Arf6 are viable. This may reflect conditional requirements for Arf6 signaling in specific cell types or under distinct physiological conditions. For example, in HepG2 cells, Arf6 mediates InR signaling (downstream of CNK1, a direct interactor with the Arf6 activator cytohesin-2; Lim et al., 2010). In contrast, Arf6 is not necessary for immediate downstream InR signaling in 3T3-L1 adipocytes (Yang and Mueckler, 1999; Bose et al., 2001; Lawrence and Birnbaum, 2001; Li et al., 2012). We show that InR signaling in Drosophila neurons and S2 cells requires Arf6.

Our data show that adult increases in InR signaling caused resistance to ethanol-induced sedation. This is in contrast to findings by Eddison et al. (2011) showing that strong increases in InR signaling throughout development and into adulthood led to ethanol sensitivity. This may be explained by the developmental effects of insulin signaling on neural proliferation (McClure et al., 2011) and wiring (Song and Zinsmaier, 2003), overriding any opposing effects from adult InR changes. In addition, the InR pathway is known to be under homeostatic regulation (Copps and White, 2012; Boucher et al., 2014) and the adult behavioral phenotypes observed after developmental interference with InR signaling (Eddison et al., 2011; McClure et al., 2011) could therefore be due to a homeostatic upregulation of the signaling pathway after suppressing the pathway through development.

\section{Role for S6k in ethanol-induced sedation}

Pioneering work showed that S6k is activated in the nucleus accumbens of rodents that were injected with a
A

Ethanol $\quad 0 \quad 80 \quad 110 \quad 130 \quad 150$ \% Sedation - $\begin{array}{llll}20 & 68 & 81 & 100\end{array}$

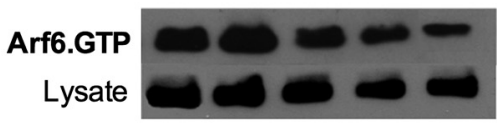

B

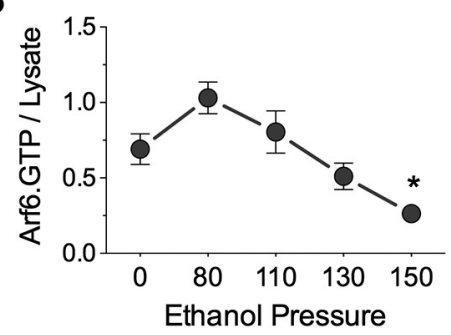

C

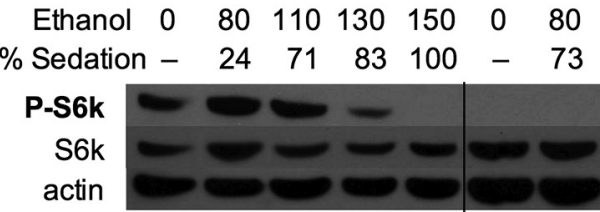

D

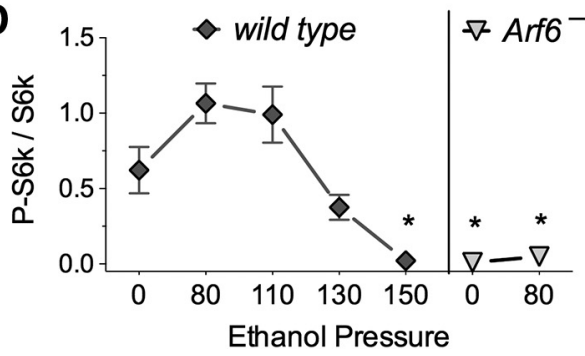

Figure 4. Acute ethanol exposure affects adult fly InR signaling in vivo. $A, B$, Activated Arf6.GTP pull-downs show a change in Arf6 activation as a function of ethanol exposure $\left(F_{(4,10)}=8.3, p<0.01\right.$, one-way ANOVA, $\left.n=3\right)$. There is a trend toward activation at low $\operatorname{doses}(p=0.12)$ and high doses of ethanol suppress Arf6 activity $\left[{ }^{*} p<0.05, q=3.0\right.$; Dunnett's post hoc test vs $0 / 150$ ethanol/air $(E / A)$, left lane]. $C, D$, Low doses of ethanol also show a trend toward S6k activation $(p=0.09)$, whereas high doses lead to undetectable levels of P-S6k. No P-S6kis detectable in Arf6 mutants ( ${ }^{*} p<0.05, q>3.6$; one-way ANOVA with Dunnett's posthoctestvs $0 / 150 \mathrm{E} / \mathrm{A}$ wild-type; $n=3$ ). Flies were exposed for 20 min to various doses of ethanol (combined ethanol + air flow rate was 150) and the resulting levels of sedation are indicated underneath.

A

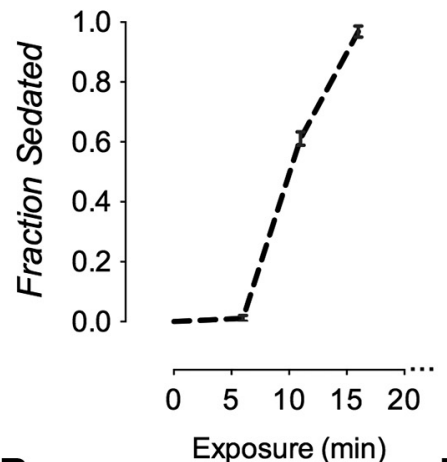

B

D

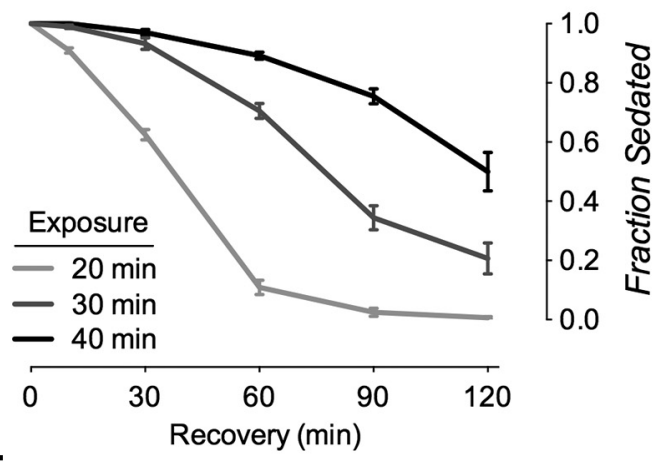

$\mathbf{E}$
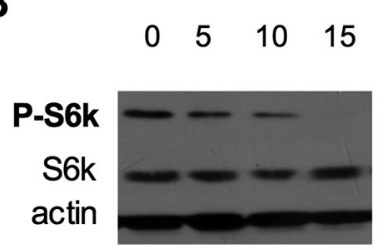

$-20-|-30-|-40-$ Exposure \begin{tabular}{llllll|llll}
30 & 60 & 120 & 30 & 60 & 120 & 30 & 60 & 120 Recovery
\end{tabular}
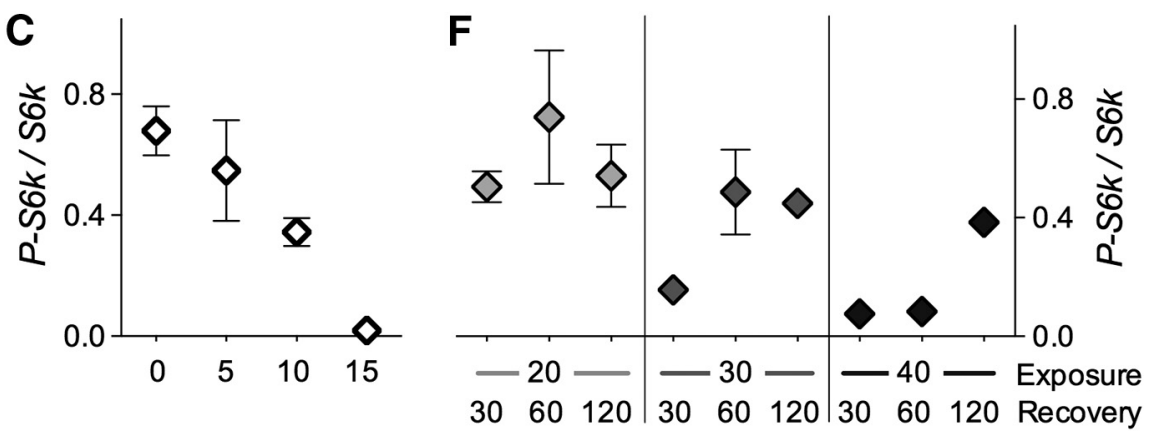

Figure 5. Levels of P-S6k correlate inversely with levels of sedation during adult ethanol exposure and recovery. $A$, Increasing duration of ethanol/air (E/A) 150/0 exposure leads to increasing sedation, with resulting loss of P-S6ksignal $(n=3 ; B, C$. D, Flies recover gradually after ethanol exposure and do so more quickly after shorter exposure (lower dose). $\boldsymbol{E}, \boldsymbol{F}$, Recovery of P-S6k signal is correlated with behavioral recovery and takes longer after a longer prior ethanol exposure (main effects of recovery, $p<0.05, F_{(2,18)}=4.2$, and exposure $p<0.001, F_{(2,18)}=13$, two-way ANOVA). The overall correlation of behavioral sedation and P-S6kmeasures in this figure is highly significant $\left(p<0.0001, r^{2}=0.56, n=36\right)$. 

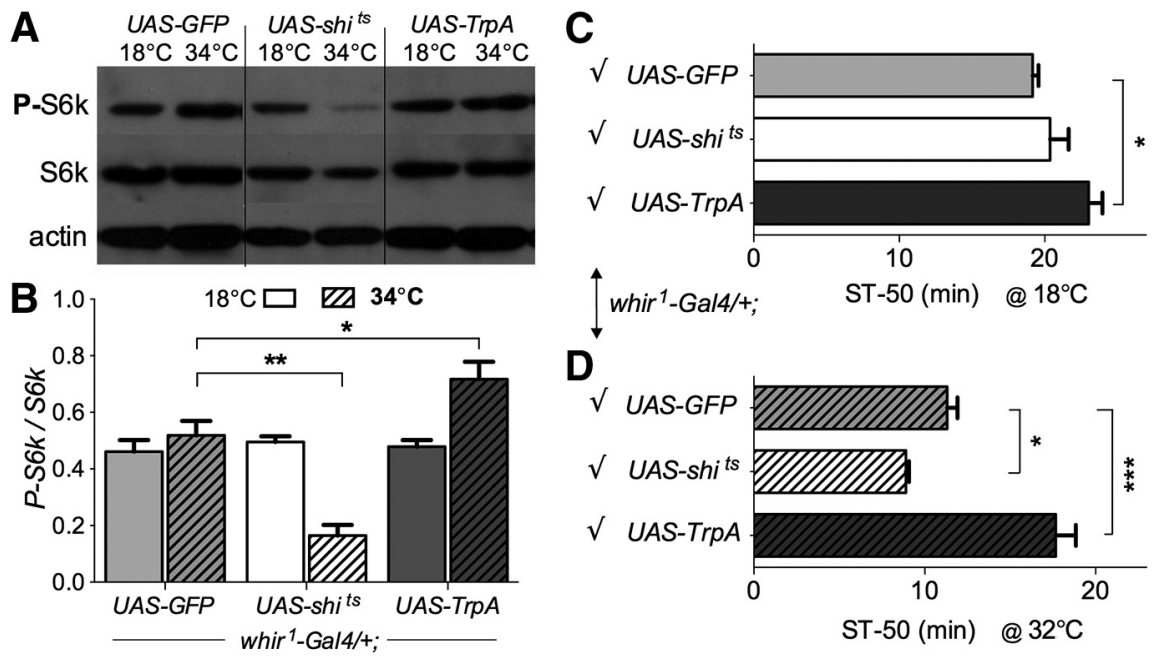

Figure 6. Neuronal activity regulates levels of P-S6k and ethanol-induced sedation. $A, B$, Shifts in temperature causing neuronal activation (TrpA) or silencing (shit ${ }^{\text {ts }}$ cause specific changes in P-S6k (no main effect of temperature, $p=0.74, F_{(1,12)}=0.12$, main effect of genotype, $p<0.001, F_{(2,12)}=21$, and significant interaction, $p<0.0001, F_{(2,12)}=24$, two-way ANOVA). Neuronal activation leads to an increase in P-S6k levels ( ${ }^{*} p<0.05, q=3.4, n=3$; Dunnett's post hoc comparison vs UAS-GFP at $34^{\circ} \mathrm{C}$ ), whereas the opposite is true for neuronal silencing $\left({ }^{* *} p<0.01, q=6.0, n=3\right)$. Flies were incubated at the effective temperature $\left(34^{\circ} \mathrm{C}\right)$ for $20 \mathrm{~min}$ before protein isolation from total heads. C, $\mathbf{D}$, Shifts in temperature causing neuronal activation (TrpA) or silencing $\left(s \mathrm{~s}^{\mathrm{ts}}\right)$ causes specific changes in sensitivity to ethanol-induced sedation (main effect of temperature, $p<0.0001, F_{(1,54)}=141$, main effect of genotype, $p<0.0001, F_{(2,54)}$ $=27$, and significant interaction, $p<0.01, F_{(2,12)}=6.7$, two-way ANOVA). Note that even wild-type flies are more sensitive to ethanolinduced sedation at higher temperature, a phenomenon that we have observed before (Rothenfluh etal., 2006). Ethanol-induced sedation is suppressed by TrpA-mediated neuronal activation ( ${ }^{* * *} p<0.001, q=6.1, n=12$, Dunnett's post hoc comparison vs UAS-GFP; $\boldsymbol{D}$ ) and enhanced by shit ${ }^{\text {ts }}$-mediated neuronal silencing $\left({ }^{*} p<0.05, q=2.5, n=15,12\right) .32^{\circ} \mathrm{C}$ was used as the effective temperature because a significant fraction of TrpA flies had seizures at $34^{\circ}$. At $18^{\circ} \mathrm{C}$, no behavioral effects were observed in UAS-shi ${ }^{\text {ts }}$, but UAS-TrpA showed a small increase in resistance to sedation, probably due to some leakiness of the channel even at low temperatures ( ${ }^{*} p<0.05, q=2.8, n=7,7$; C. For all panels, transgenes were driven by whir ${ }^{1}-G a / 4 /+$, which expresses in neurons mediating sedation (Rothenfluh et al., 2006), and were exposed to $110 / 40$ ethanol/air (E/A).

nonsedating dose or that self-administered ethanol (Neasta et al., 2010). In addition, pharmacological inhibition of mTOR (a direct activator or $\mathrm{S6} \mathrm{k}$ ) with rapamycin led to a reduction in acute ethanol intake (Neasta et al., 2010) and drinking relapse (Barak et al., 2013). Therefore, mTOR and S6k appear to be positive mediators of ethanol drinking (Neasta et al., 2014) and the pathway is induced by acute ethanol exposure (Neasta et al., 2010) and even ethanol-associated memories (Barak et al., 2013). Here, we show for the first time a direct role for S6k in regulating behavioral responses to ethanol. Increasing adult neuronal activity of S6k or its upstream regulator, InR, leads to a decrease in ethanol sensitivity. Conversely, decreasing the activity of Arf6, another upstream regulator of S6k, increases ethanol sensitivity. We also observed a trend toward activation of the pathway by nonsedating doses of ethanol, similar to observations in mammalian studies (Neasta et al., 2010). Because addiction is a result of both sensitivity to the reinforcing effects of ethanol and resistance to its intoxicating/sedating effects (Newlin and Thomson, 1990; Schuckit, 1994; King et al., 2011; Quinn and Fromme, 2011), S6k may play a role both in the activating, nonsedating limb of ethanol-induced behavior and reinforcement (Neasta et al., 2010) and in the intoxicating, aversive limb of ethanol-induced behavior (this study).

\section{Physiological role of S6k activity}

We demonstrate that an acute, sedating dose of ethanol causes loss of S6k activity. In addition, we show that behavioral recovery from sedation correlates with molecular recovery of S6k activity. If S6k activity both reflects and regulates ethanol- induced sedation, what might be the underlying physiological process that is relevant to these functions? Recently, Knight et al. (2012) showed that, in the mouse brain, activity of S6k reflects neuronal activation. Loss of P-S6k by acute ethanol exposure might thus reflect loss of neural activity. Indeed, when we increased neurons' activity with the temperature-gated $\operatorname{TrpA}$ cation channel, we were able to suppress ethanol-induced sedation, whereas silencing neurons with shits ${ }^{\text {ts }}$ led to enhanced sensitivity. This suggests that ethanol causes loss of neural activity, likely via the inhibition of numerous membrane channel targets (Olsen et al., 2014; Trudell et al., 2014), which in turn leads to downregulation of S6k. In addition, alterations in InR, mTOR, and S6k signaling alter both the strength and size of synapses in mammals and flies (Tavazoie et al., 2005; Martín-Peña et al., 2006; Knox et al., 2007; Bateup et al., 2011). Therefore, stronger synapses achieved by activating the InR pathway would predispose animals to be more resistant to ethanol-induced loss of neural activity and consequently sedation. Neuronal InR signaling, mediated by the small GTPase Arf6 and by S6k, is therefore a critical pathway for acute neural activation and inhibition by ethanol.

\section{References}

Barak S, Liu F, Ben Hamida S, Yowell QV, Neasta J, Kharazia V, Janak PH, Ron D (2013) Disruption of alcohol-related memories by mTORC1 inhibition prevents relapse. Nat Neurosci 16:1111-1117. CrossRef Medline

Bateup HS, Takasaki KT, Saulnier JL, Denefrio CL, Sabatini BL (2011) Loss of Tscl in vivo impairs hippocampal mGluR-LTD and increases excitatory synaptic function. J Neurosci 31:8862-8869. CrossRef Medline

Bjedov I, Toivonen JM, Kerr F, Slack C, Jacobson J, Foley A, Partridge L (2010) Mechanisms of life span extension by rapamycin in the fruit fly Drosophila melanogaster. Cell Metab 11:35-46. CrossRef Medline

Bose A, Cherniack AD, Langille SE, Nicoloro SM, Buxton JM, Park JG, Chawla A, Czech MP (2001) G(alpha)11 signaling through ARF6 regulates F-actin mobilization and GLUT4 glucose transporter translocation to the plasma membrane. Mol Cell Biol 21:5262-5275. CrossRef Medline

Boucher J, Kleinridders A, Kahn CR (2014) Insulin receptor signaling in normal and insulin-resistant states. Cold Spring Harb Perspect Biol 6.

Copps KD, White MF (2012) Regulation of insulin sensitivity by serine/ threonine phosphorylation of insulin receptor substrate proteins IRS1 and IRS2. Diabetologia 55:2565-2582. CrossRef Medline

Corl AB, Rodan AR, Heberlein U (2005) Insulin signaling in the nervous system regulates ethanol intoxication in Drosophila melanogaster. Nat Neurosci 8:18-19. CrossRef Medline

Eddison M, Guarnieri DJ, Cheng L, Liu CH, Moffat KG, Davis G, Heberlein U (2011) arouser reveals a role for synapse number in the regulation of ethanol sensitivity. Neuron 70:979-990. CrossRef Medline

Gelernter J, Kranzler HR (2009) Genetics of alcohol dependence. Hum Genet 126:91-99. CrossRef Medline

Goldman D, Ducci F (2007) Deconstruction of vulnerability to complex diseases: enhanced effect sizes and power of intermediate phenotypes. ScientificWorldJournal 7:124-130. CrossRef Medline

Hamada FN, Rosenzweig M, Kang K, Pulver SR, Ghezzi A, Jegla TJ, Garrity 
PA (2008) An internal thermal sensor controlling temperature preference in Drosophila. Nature 454:217-220. CrossRef Medline

Kaun KR, Azanchi R, Maung Z, Hirsh J, Heberlein U (2011) A Drosophila model for alcohol reward. Nat Neurosci 14:612-619. CrossRef Medline

King AC, de Wit H, McNamara PJ, Cao D (2011) Rewarding, stimulant, and sedative alcohol responses and relationship to future binge drinking. Arch Gen Psychiatry 68:389-399. CrossRef Medline

Kitamoto T (2001) Conditional modification of behavior in Drosophila by targeted expression of a temperature-sensitive shibire allele in defined neurons. J Neurobiol 47:81-92. CrossRef Medline

Knight ZA, Tan K, Birsoy K, Schmidt S, Garrison JL, Wysocki RW, Emiliano A, Ekstrand MI, Friedman JM (2012) Molecular profiling of activated neurons by phosphorylated ribosome capture. Cell 151:1126-1137. CrossRef Medline

Knox S, Ge H, Dimitroff BD, Ren Y, Howe KA, Arsham AM, Easterday MC, Neufeld TP, O'Connor MB, Selleck SB (2007) Mechanisms of TSCmediated control of synapse assembly and axon guidance. PLoS One 2:e375. CrossRef Medline

Lawrence JT, Birnbaum MJ (2001) ADP-ribosylation factor 6 delineates separate pathways used by endothelin 1 and insulin for stimulating glucose uptake in 3T3-L1 adipocytes. Mol Cell Biol 21:5276-5285. CrossRef Medline

Lee HG, Kim YC, Dunning JS, Han KA (2008) A Recurring ethanol exposure induces disinhibited courtship in Drosophila. PLoS One 3:e1391. CrossRef Medline

Li J, Malaby AW, Famulok M, Sabe H, Lambright DG, Hsu VW (2012) Grp1 plays a key role in linking insulin signaling to glut4 recycling. Dev Cell 22:1286-1298. CrossRef Medline

Lim J, Zhou M, Veenstra TD, Morrison DK (2010) The CNK1 scaffold binds cytohesins and promotes insulin pathway signaling. Genes Dev 24:1496-1506. CrossRef Medline

Liu Q, Liu S, Kodama L, Driscoll MR, Wu MN (2012) Two dopaminergic neurons signal to the dorsal fan-shaped body to promote wakefulness in Drosophila. Curr Biol 22:2114-2123. CrossRef Medline

Lizcano JM, Alrubaie S, Kieloch A, Deak M, Leevers SJ, Alessi DR (2003) Insulin-induced Drosophila S6 kinase activation requires phosphoinositide 3-kinase and protein kinase B. Biochem J 374:297-306. CrossRef Medline

Martín-Peña A, Acebes A, Rodríguez JR, Sorribes A, de Polavieja GG, Fernández-Fúnez P, Ferrús A (2006) Age-independent synaptogenesis by phosphoinositide 3 kinase. J Neurosci 26:10199-10208. CrossRef Medline

McClure KD, French RL, Heberlein U (2011) A Drosophila model for fetal alcohol syndrome disorders: role for the insulin pathway. Dis Model Mech 4:335-346. CrossRef Medline

Montagne J, Stewart MJ, Stocker H, Hafen E, Kozma SC, Thomas G (1999) Drosophila S6 kinase: a regulator of cell size. Science 285:2126-2129. CrossRef Medline

Neasta J, Ben Hamida S, Yowell Q, Carnicella S, Ron D (2010) Role for mammalian target of rapamycin complex 1 signaling in neuroadaptations underlying alcohol-related disorders. Proc Natl Acad Sci U S A 107: 20093-20098. CrossRef Medline

Neasta J, Barak S, Hamida SB, Ron D (2014) mTOR complex 1: a key player in neuroadaptations induced by drugs of abuse. J Neurochem 130:172184. CrossRef Medline

Newlin DB, Thomson JB (1990) Alcohol challenge with sons of alcoholics: a critical review and analysis. Psychol Bull 108:383-402. CrossRef Medline

Offenhäuser N, Castelletti D, Mapelli L, Soppo BE, Regondi MC, Rossi P, D’Angelo E, Frassoni C, Amadeo A, Tocchetti A, Pozzi B, Disanza A, Guarnieri D, Betsholtz C, Scita G, Heberlein U, Di Fiore PP (2006) Increased ethanol resistance and consumption in Eps8 knockout mice correlates with altered actin dynamics. Cell 127:213-226. CrossRef Medline

Olsen RW, Li GD, Wallner M, Trudell JR, Bertaccini EJ, Lindahl E, Miller KW, Alkana RL, Davies DL (2014) Structural models of ligand-gated ion channels: sites of action for anesthetics and ethanol. Alcohol Clin Exp Res 38:595-603. CrossRef Medline

Palamidessi A, Frittoli E, Garré M, Faretta M, Mione M, Testa I, Diaspro A, Lanzetti L, Scita G, Di Fiore PP (2008) Endocytic trafficking of Rac is required for the spatial restriction of signaling in cell migration. Cell 134:135-147. CrossRef Medline

Peru y Colon de Portugal RL, Acevedo SF, Rodan AR, Chang LY, Eaton BA, Rothenfluh A (2012) Adult neuronal Arf6 controls ethanol-induced behavior with Arfaptin downstream of Rac1 and RhoGAP18B. J Neurosci 32:17706-17713. CrossRef Medline

Quinn PD, Fromme K (2011) Subjective response to alcohol challenge: a quantitative review. Alcohol Clin Exp Res 35:1759-1770. CrossRef Medline

Rietschel M, Treutlein J (2013) The genetics of alcohol dependence. Ann N Y Acad Sci 1282:39-70. CrossRef Medline

Rodan AR, Rothenfluh A (2010) The genetics of behavioral alcohol responses in Drosophila. Int Rev Neurobiol 91:25-51. CrossRef Medline

Rothenfluh A, Threlkeld RJ, Bainton RJ, Tsai LT, Lasek AW, Heberlein U (2006) Distinct behavioral responses to ethanol are regulated by alternate RhoGAP18B isoforms. Cell 127:199-211. CrossRef Medline

Schuckit MA (1994) Low level of response to alcohol as a predictor of future alcoholism. Am J Psychiatry 151:184-189. CrossRef Medline

Schweitzer JK, Sedgwick AE, D'Souza-Schorey C (2011) ARF6-mediated endocytic recycling impacts cell movement, cell division and lipid homeostasis. Semin Cell Dev Biol 22:39-47. CrossRef Medline

Song W, Zinsmaier KE (2003) Endophilin and synaptojanin hook up to promote synaptic vesicle endocytosis. Neuron 40:665-667. CrossRef Medline

Tavazoie SF, Alvarez VA, Ridenour DA, Kwiatkowski DJ, Sabatini BL (2005) Regulation of neuronal morphology and function by the tumor suppressors Tsc1 and Tsc2. Nat Neurosci 8:1727-1734. CrossRef Medline

Trudell JR, Messing RO, Mayfield J, Harris RA (2014) Alcohol dependence: molecular and behavioral evidence. Trends Pharmacol Sci 35:317-323. CrossRef Medline

Weinkove D, Neufeld TP, Twardzik T, Waterfield MD, Leevers SJ (1999) Regulation of imaginal disc cell size, cell number and organ size by Drosophila class I(A) phosphoinositide 3-kinase and its adaptor. Curr Biol 9:1019-1029. CrossRef Medline

Wolf FW, Rodan AR, Tsai LT, Heberlein U (2002) High-resolution analysis of ethanol-induced locomotor stimulation in Drosophila. J Neurosci 22: 11035-11044. Medline

Yang CZ, Mueckler M (1999) ADP-ribosylation factor 6 (ARF6) defines two insulin-regulated secretory pathways in adipocytes. J Biol Chem 274: 25297-25300. CrossRef Medline 